\title{
Nef Obtained from Individuals with HIV-1 Vary in Their Ability to Antagonize SERINC3- and SERINC5-Mediated HIV-1 Restriction
}

\author{
Zita Kruize, Ad C. van Nuenen, Stan W. van Wijk (D, Arginell F. Girigorie, Karel A. van Dort, Thijs Booiman ${ }^{\dagger}$ \\ and Neeltje A. Kootstra *D
}

\section{check for}

updates

Citation: Kruize, Z.; van Nuenen, A.C.; van Wijk, S.W.; Girigorie, A.F.; van Dort, K.A.; Booiman, T.; Kootstra, N.A. Nef Obtained from Individuals with HIV-1 Vary in Their Ability to Antagonize SERINC3- and SERINC5-Mediated HIV-1 Restriction. Viruses 2021, 13, 423. https:// doi.org/10.3390/v13030423

Academic Editor: Susana

Tereno Valente

Received: 7 January 2021

Accepted: 2 March 2021

Published: 6 March 2021

Publisher's Note: MDPI stays neutral with regard to jurisdictional claims in published maps and institutional affiliations.

Copyright: (c) 2021 by the authors. Licensee MDPI, Basel, Switzerland. This article is an open access article distributed under the terms and conditions of the Creative Commons Attribution (CC BY) license (https:// creativecommons.org/licenses/by/ $4.0 /)$.
Department of Experimental Immunology, Amsterdam UMC, Amsterdam Infection \& Immunity Institute, University of Amsterdam, 1105 AZ Amsterdam, The Netherlands; z.kruize@amsterdamumc.nl (Z.K.); a.c.vannuenen@amsterdamumc.nl (A.C.v.N.); s.w.vanwijk@amsterdamumc.nl (S.W.v.W.); a.f.girigorie@amsterdamumc.nl (A.F.G.); k.a.vandort@amsterdamumc.nl (K.A.v.D.); tbooiman@halix.nl (T.B.)

* Correspondence: n.a.kootstra@amsterdamumc.nl; Tel.: +31-205-668-298

+ Current address: Halix B.V., Tinbergenweg 1, 2333 BB Leiden, The Netherlands.

Abstract: Nef is a multifunctional viral protein that has the ability to downregulate cell surface molecules, including CD4 and major histocompatibility complex class I (MHC-I) and, as recently shown, also members of the serine incorporator family (SERINC). Here, we analyzed the impact of naturally occurring mutations in HIV-1 Nef on its ability to counteract SERINC restriction and the clinical course of infection. HIV-1 Nef sequences were obtained from 123 participants of the Amsterdam Cohort Studies and showed multiple amino acid variations and mutations. Most of the primary Nef proteins showed increased activity to counteract SERINC3 and SERINC5 as compared to NL4-3 Nef. Several mutations in Nef were associated with either an increased or decreased infectivity of Bal26-pseudotyped HIV-1 produced in the presence of SERINC3 or SERINC5. The 8R, 157N and R178G Nef mutations were shown to have an effect on disease progression. Survival analysis showed an accelerated disease progression of individuals infected with HIV-1 carrying arginine or asparagine at position 8 or 157 in Nef, respectively, or the R178G Nef mutation. Here, we observed that naturally occurring mutations in Nef affect the ability of Nef to counteract SERINC3- and SERINC5-mediated inhibition of viral infectivity. The majority of these Nef mutations had no significant effect on HIV-1 pathogenesis and only the $8 \mathrm{R}, 157 \mathrm{~N}$ and R178G mutations were associated with disease course.

Keywords: HIV-1; Nef; SERINC3; SERINC5; amino acid variations; naturally occurring mutations; disease progression

\section{Introduction}

Nef is a 27-32-kilodalton (kDa) accessory protein encoded by HIV-1 and other primate lentiviruses. Nef is a multifunctional viral protein that has the ability to downregulate cell surface molecules, including CD4, major histocompatibility complex class I (MHC-I) and Tcell receptor, via clathrin-dependent endocytosis and subsequent lysosomal degradation [1]. Nef's ability to internalize CD4 and MHC-I from an infected cell surface allows HIV-1 to evade antibody-dependent cellular cytotoxicity (ADCC) and cytotoxic T lymphocytes (CTLs) [2-5]. Nef can also alter the activation state of T cells and macrophages and perturbs the actin cytoskeleton by engaging with cellular kinases [6-8].

One of the most conserved but poorly understood functions of Nef is the enhancement of progeny virion infectivity. Nef-mediated enhancement of viral infectivity was recently shown to be due, in part, to its ability to counteract members of the serine incorporator family (SERINC). SERINC proteins are host restriction factors, of which SERINC5 was shown to be the most potent one $[9,10]$. SERINC5 can be incorporated in the membrane of progeny virions, which subsequently inhibits infection of new target cells at the level of membrane fusion [11]. HIV-1 Nef has been shown to prevent SERINC5 incorporation 
into the virion and thus counteracts the SERINC5-mediated restriction. Nef interacts with SERINC5 on the cell surface, and upon internalization, SERINC5 is targeted for lysosomal degradation [12]. Several Nef mutations involved, among others, in myristoylation, dimerization and interaction with the clathrin- and adaptor protein complex 2 (AP-2) are reported to impair the Nef function [13-16]. Although a role of SERINC in HIV-1 replication has clearly been demonstrated, the impact of naturally occurring mutations in HIV-1 Nef on its ability to counteract SERINC restriction and the clinical course of infection is not well known. In this study, we assessed if naturally occurring, previously described genetic variation and mutations in the identified binding sites and mutations of HIV-1 Nef have an effect on the ability to counteract SERINC3 and SERINC5. Moreover, we determined the effect of these mutations on disease progression during the natural course of infection in the Amsterdam Cohort Studies.

\section{Materials and Methods}

\subsection{Study Population}

The study population consisted of men having sex with men (MSM) enrolled in the Amsterdam Cohort Studies (ACS) on the natural history of HIV-1 infection between October 1984 and February 1988. HIV-1 Nef sequences were obtained from 123 participants with known date of seroconversion and documented AIDS diagnosis or follow-up of at least 7 years without an AIDS diagnosis [17]. All participants in this study were infected with subtype B HIV-1.

\subsection{Ethics Statement}

The ACS has been conducted in accordance with the ethical principles set out in the Declaration of Helsinki, and written informed consent was obtained prior to data collection. The study was approved by the Amsterdam Medical Center institutional medical ethics committee (MEC 07/182, 20 August 2007).

\subsection{HIV-1 Nef Sequencing}

Clonal HIV-1 variants or bulk isolates were obtained as described previously [18] and total DNA was isolated using the L6 isolation method. Nef was amplified using a nested PCR with the outer primers Nef-1-fw (5'-AGCCATAGCAGTAGCTGAGG-3') and Nef-1-rev (5'-GCTTATATGCAGGATCTGAGG-3') and the inner primers Nef-2-fw $\left(5^{\prime}-\right.$ AGCTTGTAGAGCTATTCGCCACA-3') and Nef-2-rev (5'-AGCAAGCTCGATGTCAGCAG$3^{\prime}$ ). Nef PCRs were performed using Taq polymerase (Promega, Madison, WI, USA) in the presence of $2 \mathrm{mM} \mathrm{MgCl} 2$ using the following amplification cycles: $2 \mathrm{~min}$ at $95^{\circ} \mathrm{C}, 35$ cycles of $30 \mathrm{~s}$ at $95^{\circ} \mathrm{C}, 30 \mathrm{~s}$ at $55^{\circ} \mathrm{C}, 2 \mathrm{~min}$ at $72{ }^{\circ} \mathrm{C}$, followed by a 10 -min extension at $72{ }^{\circ} \mathrm{C}$ and subsequent cooling to $4^{\circ} \mathrm{C}$. PCR products were purified using EXOSAP-IT reagent (USB, Cleveland, OH, USA) and sequenced using an ABI prism Big Dye Terminator v1.1 Cycle Sequencing Kit (Applied Biosystems, Foster City, CA, USA) using the nested PCR primers. Sequences were analyzed on the Applied Biosystems/Hitachi 3130 xl Genetic Analyzer (Foster City, CA, USA). DNA sequences were translated and analyzed with the BioEdit program (BioEdit v 7.0.5, Tom Hall, Ibis Therapeutics, Carlsbad, CA, USA).

\subsection{Plasmids}

SERINC3- and SERINC5-expressing constructs were constructed by cloning complementary DNA (cDNA) of SERINC3 and SERINC5 into a HIV-1-based lentiviral expression vector in which expression was driven by the human Elongation Factor 1 alpha promotor, using the In-Fusion ${ }^{\circledR}$ HD Cloning kit as described by the manufacturer (Clontech ${ }^{\circledR}$ Laboratories, Inc., Mountain View, CA, USA). Sanger sequencing demonstrated that the cloned cDNA matched the reference sequence (accession number NM_001174072.2 for SERINC5 and NM_006811 for SERINC3). Constructs expressing the HIV-1 Nef protein were constructed as follows: Nef from primary HIV-1 isolates from individuals participating in the Amsterdam Cohort Studies and NL4-3 were amplified by PCR and cloned in pcDNA3.1 
(Invitrogen, Carlsbad, CA, USA) using the In-Fusion ${ }^{\circledR}$ HD Cloning kit as described by the manufacturer (Clontech ${ }^{\circledR}$ Laboratories, Inc., Mountain View, CA, USA). The S163C, R178G and double mutants were created from NL4-3 Nef with site-directed mutagenesis.

\subsection{Cell Lines}

HEK293T cells (ATCC®CRL-3216 ${ }^{\mathrm{TM}}$ )were cultured in Dulbecco's Modified Eagle Medium without HEPES (DMEM) (Lonza, Basel, Switzerland) supplemented with 10\% (v/v) inactivated fetal calf serum (FCS; HyClone, Cytiva, Marlborough, MA, USA), penicillin $(100 \mathrm{U} / \mathrm{mL})$ and streptomycin $(100 \mu \mathrm{g} / \mathrm{mL})$ (Invitrogen, Carlsbad, CA, USA) and maintained in a humidified $10 \% \mathrm{CO}_{2}$ incubator at $37^{\circ} \mathrm{C}$. U87 $/ \mathrm{CD}^{+}-\mathrm{CCR} 5^{+}$cells (NIH AIDS reagent program) [19] were cultured in Iscove's modified Dulbecco medium (Lonza, Basel, Switzerland) supplemented with $10 \%(v / v)$ inactivated FCS, penicillin $(100 \mathrm{U} / \mathrm{mL})$ and streptomycin $(100 \mu \mathrm{g} / \mathrm{mL})$, treated once a month with G418 (Sigma-Aldrich St. Louis, MO, USA) and maintained in a humidified $5 \% \mathrm{CO}_{2}$ incubator at $37^{\circ} \mathrm{C}$.

\subsection{Virus Production}

Bal26-pseudotyped NL4-3.Luc.R-E- luciferase reporter virus, for single-cycle replication assays, was produced by transfection of pNL4-3.Luc.R-E- [20-22] with pEnv Bal26 in HEK293T cells. The luciferase reporter virus was produced in HEK293T cells co-transfected in a 6-well plate with plasmids expressing Nef and SERINC3 or SERINC5 alone or in combination. In a 6-well plate, $7.18 \mu \mathrm{g}$ of pNL4-3.Luc.R-E-, $2.51 \mu \mathrm{g}$ of pEnv Bal26, $2.51 \mu \mathrm{g}$ of plasmid expressing Nef or empty pcDNA3.1 vector (Invitrogen, Carlsbad, CA, USA) and $2.51 \mu \mathrm{g}$ of plasmid expressing SERINC3, SERINC5 or empty lentiviral vector were co-transfected. Transfections were performed using the calcium phosphate method. In short, plasmid DNA was diluted in $0.042 \mathrm{M} \mathrm{HEPES} \mathrm{containing} 0.2 \mathrm{M} \mathrm{CaCl}_{2}$ and subsequently mixed with an equal volume of $2 \times$ HEPES-buffered saline $\mathrm{pH} 7.2$, incubated at room temperature for $15 \mathrm{~min}$ and added to the culture medium. After $24 \mathrm{~h}$ incubation in a humidified $3 \% \mathrm{CO}_{2}$ incubator at $37^{\circ} \mathrm{C}$, the culture medium was replaced and cultures were continued at $10 \% \mathrm{CO}_{2}$ at $37{ }^{\circ} \mathrm{C}$. Virus was harvested at 72 and $96 \mathrm{~h}$ after transfection and passed through a $0.22-\mu \mathrm{m}$ filter.

\subsection{Flow Cytometry}

HEK293T cells were cultured in 6-well plates and co-transfected with plasmids expressing Nef and SERINC3 or SERINC5 as described above. Cells were harvested with phosphate buffered saline (PBS; Lonza, Basel, Switzerland) supplemented with 10mM EDTA (Sigma-Aldrich St. Louis, MO, USA). HEK293T cells were stained with anti-SERINC3 (1:500, Abcam, Cambridge, UK) and anti-SERINC5 (4 $\mathrm{g} / \mathrm{mL}$, Abcam, Cambridge, UK) for 30 min at $4{ }^{\circ} \mathrm{C}$ in the dark. Subsequently, cells were washed twice with PBS supplemented with $0.5 \%$ bovine serum albumin (BSA; Sigma-Aldrich St. Louis, MO, USA) followed by staining with an allophycocyanin (APC)-conjugated goat anti-rabbit (1:400; Invitrogen, Carlsbad, CA, USA) for $30 \mathrm{~min}$ at $4{ }^{\circ} \mathrm{C}$ in the dark. Subsequently, cells were washed again with PBS supplemented with $0.5 \%$ BSA and fixed using $250 \mathrm{~mL}$ of BD CellFIX (BD Biosciences, Franklin Lakes, NJ, USA). Fluorescence was measured with the FACSCanto II analyzer (BD Biosciences, Franklin Lakes, NJ, USA). The geometric mean of the fluorescence intensity of APC was determined using FlowJo 10 (TreeStar, Ashland, OR, USA).

\subsection{Western Blot Analysis}

HEK293T cells were cultured in 6-well plates and transfected with plasmids expressing Nef as described above. Two days post-transfection, HEK293T cells were lysed in RIPA-buffer (150 mM NaCl, 1\% Triton X-100, 0.5\% sodium deoxycholate, 0.1\% SDS, $50 \mathrm{mM}$ Tris, pH 8.0) containing Complete EDTA-free protease inhibitor (Roche, Basel, Switserland). After adding NuPAGE LDS $4 \times$ sample buffer (Invitrogen, Carlsbad, CA, USA) and $0.1 \mathrm{M}$ dithiothreitol (DTT; Invitrogen, Carlsbad, CA, USA), samples were heated at $95{ }^{\circ} \mathrm{C}$ for 10 min. Proteins were separated by SDS-PAGE (NuPAGE 4-12\% Bis-Tris precast gel and 
MES SDS running buffer (Invitrogen, Carlsbad, CA, USA) and transferred to a nitrocellulose membrane (Protran, Schleicher and Schuell, Dassel, Germany) using NuPAGE transfer buffer (Invitrogen, Carlsbad, CA, USA). After blocking for $2 \mathrm{~h}$ with PBS containing 5\% Protifar (Nutricia, Schiphol, The Netherlands) and 0.5\% BSA, the blot was incubated with anti-c-Myc antibody (1:5000; Calbiochem, San Diego, CA, USA) and anti- $\beta$-actin antibody (1:200; Santa Cruz Biotechnology, Santa Cruz, CA, USA). IRDye 800CW conjugated goat anti-mouse IgG (1:15000, LI-COR, Lincoln, NE, USA) and IRDye 680LT conjugated donkey anti-goat IgG (1:15000, LI-COR) were used as secondary antibodies to visualize expression using the proteins.

\subsection{Viral Infection}

To analyze the effect of SERINC3, SERINC5 and the primary Nef proteins on HIV-1 replication, U87 CD4+CCR5+ cells were inoculated with NL4-3 luciferase Bal26-pseudotyped single-round reporter viruses produced in the presence or absence of Nef alone or in combination with SERINC3 or SERINC5. Equal amounts of reporter viruses, as determined by an in-house p24 ELISA, were used to inoculate the target cells [23]. Luciferase activity was determined, as a measure of viral replication, $48 \mathrm{~h}$ post-infection by adding $25 \mu \mathrm{L}$ substrate ( $0.83 \mathrm{mM}$ ATP, $0.83 \mathrm{mM}$ d-luciferin (Duchefa, Haarlem, The Netherlands), $18.7 \mathrm{mM} \mathrm{MgCl}_{2}, 0.78 \mu \mathrm{M} \mathrm{Na}_{2} \mathrm{H}_{2} \mathrm{P}_{2} \mathrm{O}_{7}, 38.9 \mathrm{mM}$ Tris $\mathrm{pH} 7.8,0.39 \%(v / v)$ glycerol, $0.03 \%(v / v)$ Triton X-100 and $2.6 \mu \mathrm{M}$ dithiothreitol) directly to the culture medium. Luminescence was measured for $1 \mathrm{~s}$ per well using a luminometer (Berthold, Bad Wildbad, Germany). The infectivity of the virus produced in the presence of the primary Nef and SERINC3/5 was corrected for the infectivity of the virus produced in the presence of the same primary $\mathrm{Nef}$ and the relevant empty vector. The ability of the primary Nef proteins to counteract SERINC3/5 was expressed relative to NL4-3 Nef (fold change).

\subsection{Statistical Analysis}

Kaplan-Meier and Cox proportional hazard analyses were performed to study the relation between naturally occurring mutations in Nef and disease progression. The following endpoints were considered for analysis: AIDS-defining events including CD4+ T cell counts below 200 cells $/ \mu \mathrm{L}$ according to the 1993 Center for Disease Control (CDC) definition and AIDS-related death. Individuals who started effective combination antiretroviral therapy (cART) or who were lost to follow-up were censored. Student's $t$-test or the Mann-Whitney $U$ test was used to compare Nef activity of primary Nef from individuals with HIV-1 and wild-type NL4-3 Nef and Nef with and without naturally occurring mutations. Spearman's correlation was used to calculate the correlation between SERINC3 and SERINC5. Statistical analyses were performed using IBM SPSS Statistics for Windows v.25 (IBM, Armonk, NY, USA).

\section{Results}

\subsection{Naturally Occurring Variation in Nef}

Recent reports demonstrated that three specific sites in Nef, the amino acids 12 to 39, the ExxxLL motif (S163C) and the AP-2 binding site (R178G), were identified to be involved in Nef function [14-16,24] (Figure 1). In addition, multiple amino acid variations in Nef (subtype B HIV-1) were identified to play a role in SERINC3 and SERINC5 antagonism [14,25,26] (Figure 1) including 8R, 9S, 11P, 12G, 14A/P/S, 15A, 21K/R, 28E, 43I, N51T, 54D, 63E, 81F, H116N, 120F, V148L/X, 157N, 158K, 161N, M168I/X, 182E and 188S, of which some specifically affected SERINC3 (8R, 9S, 11P, 12G, 14A, 15A, 21K, 28E, 43I, 182E and 188S) or SERINC5 (14S, 21R, 54D, 63E, 81F, 120F, 157N and 158K) [26]. We analyzed primary Nef proteins obtained from 123 individuals with HIV-1 participating in the Amsterdam Cohort Studies for amino acid changes at the previously described positions and regions as compared to consensus B (Supplementary Table S1). In 46.3\% (57/123) of the patients, insertions of amino acids in the AA 12-39 region were observed, of which $63.2 \%$ had insertions of $1-4$ amino acids and $36.8 \%$ had insertions of $5-16$ amino 
acids (Table 1). In addition, changes in the number of positively charged amino acids were observed in $55.3 \%(68 / 123)$ of the patients, of whom $42.6 \%$ showed an increase and $57.4 \%$ showed a decrease in positively charged amino acids (Table 1). The S163C mutation in the ExxxLL motif was observed in 39.8\% (49/123) of the patients, while the R178G mutation, located in the AP-2 binding site, was observed in $17.9 \%(22 / 123)$ of the patients. The previously described polymorphisms (8R, 9S, 11P, 12G, 14A/P, 15A, 21K/R, 28E, 43I, N51T, 54D, 63E, 81F, H116N, 120F, V148L/X, 157N, 158K, 161N, M168I/X, 182E and 188S) were observed at different frequencies and are shown in Table 1. In the majority of the Nef sequences, a combination of these mutations was observed (Supplementary Table S1). For instance, a change in the number of positively charged amino acids was often observed in combination with an increased length of the AA 12-39 region (30.1\%), in combination with the S163C mutation in ExxxLL (22.8\%) or combined with both an increased length and the S163C mutation (9.8\%).
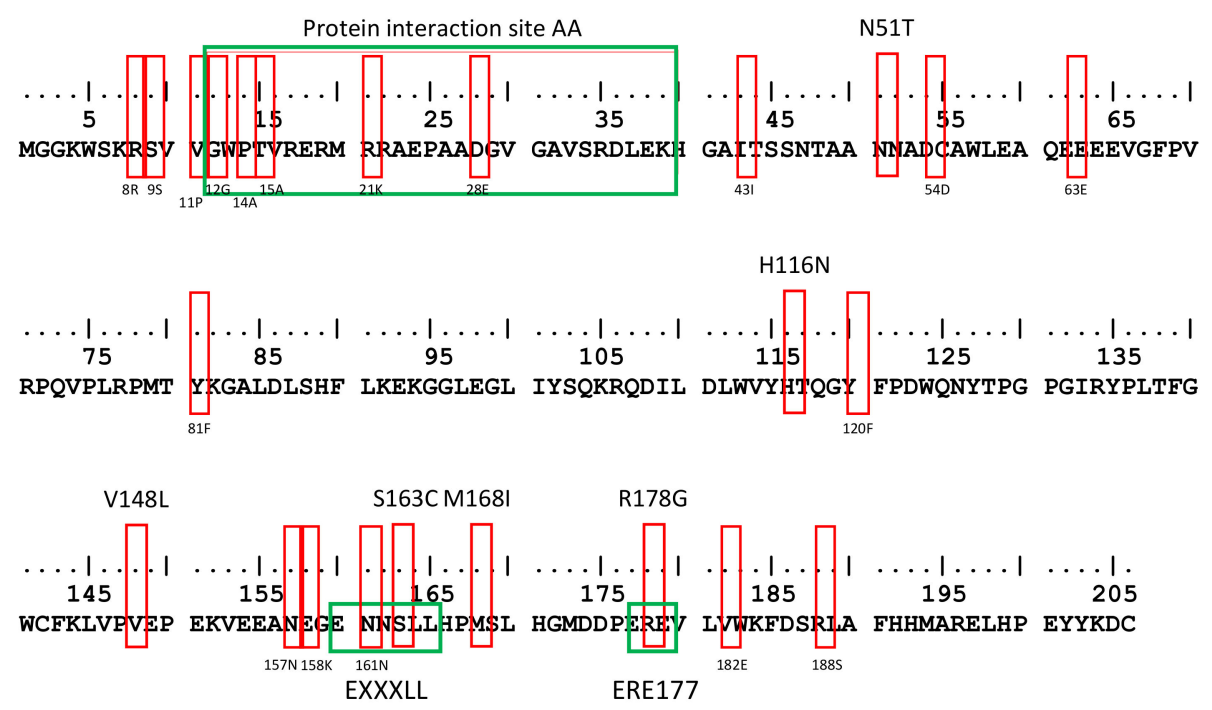

Figure 1. Amino acid variation in Nef. HIV-1 consensus B Nef. The red boxes indicate previously identified amino acid polymorphisms $[14,25,26]$. The green boxes highlight known binding sites of Nef in which naturally occurring variations and amino acid polymorphisms occur.

Table 1. Amino acid variation in HIV-1 obtained from individuals with HIV-1.

\begin{tabular}{|c|c|c|c|}
\hline \multicolumn{2}{|c|}{ Nef Variation } & \multicolumn{2}{|c|}{$\%$ of Patients $(n) n=123$} \\
\hline \multicolumn{4}{|c|}{ Protein interaction site (AA 12-39): } \\
\hline \multicolumn{2}{|c|}{ Extra length } & \multicolumn{2}{|c|}{$46.3 \%(57)$} \\
\hline \multicolumn{2}{|c|}{ Change of charge } & \multicolumn{2}{|c|}{$55.3 \%(68)$} \\
\hline \multicolumn{4}{|c|}{ Amino acid polymorphisms: } \\
\hline $8 \mathrm{R}$ & $52.0 \%(64)$ & $81 \mathrm{~F}$ & $10.6 \%(13)$ \\
\hline 9S & $63.4 \%(78)$ & $\mathrm{H} 116 \mathrm{~N}$ & $17.9 \%(22)$ \\
\hline $11 \mathrm{P}$ & $5.7 \%(7)$ & $120 \mathrm{~F}$ & $6.5 \%(8)$ \\
\hline $12 \mathrm{G}$ & $82.1 \%(101)$ & V148L/V148X & $10.6 \%(13) / 13.8 \%$ \\
\hline $14 \mathrm{~A} / 14 \mathrm{P}$ & $5.7 \%(7) / 25.2 \%(31)$ & $157 \mathrm{~N}$ & $85.4 \%(105)$ \\
\hline $15 \mathrm{~A}$ & $52.8 \%(65)$ & $158 \mathrm{~K}$ & $11.4 \%(14)$ \\
\hline $21 \mathrm{~K} / 21 \mathrm{R}$ & $11.4 \%(14) / 64.2 \%(79)$ & $161 \mathrm{~N}$ & $93.5 \%(115)$ \\
\hline $28 \mathrm{E}$ & $35.8 \%(44)$ & S163C & $39.8 \%(49)$ \\
\hline $43 I$ & $82.1 \%(101)$ & M168I/M168X & $22.0 \%(27) / 27.6 \%$ \\
\hline N51T & $61.8 \%(76)$ & R178G & $17.9 \%(22)$ \\
\hline $54 \mathrm{D}$ & $78.0 \%(96)$ & $182 \mathrm{E}$ & $19.5 \%(24)$ \\
\hline $63 \mathrm{E}$ & $79.7 \%(98)$ & $188 \mathrm{~S}$ & $6.5 \%(8)$ \\
\hline
\end{tabular}




\subsection{Effect of Naturally Occurring Amino Acid Variations on Nef Activity to Counteract SERINC3 and SERINC5}

To assess the ability of HIV-1 Nef to counteract the SERINC3- and SERINC5-mediated inhibition of viral infectivity, SERINC3 and SERINC5 were overexpressed in HEK293T cells, either alone or combined with HIV-1 Nef. Subsequently, the surface expression of SERINC3 and SERINC5 was determined. We observed that the geometric mean of fluorescence intensity for SERINC3 and SERINC5 decreased significantly $(p<0.05)$ in the presence of HIV-1 Nef, indicating a decrease in the surface expression of SERINC3 and SERINC5 by HIV-1 Nef (Figure 2A,B). The infectivity of Nef-deficient HIV-1 produced in the presence of SERINC3 or SERINC5 was reduced (Figure 2C). When a Nef protein was co-expressed during virus production, the infectivity was recovered (Figure 2C).

A

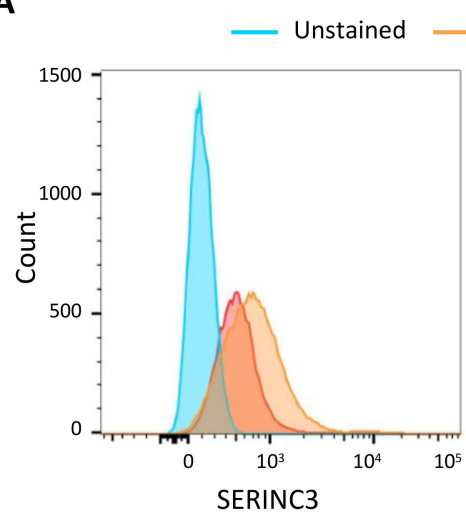

Serinc3/5 Serinc $3 / 5+$ Nef

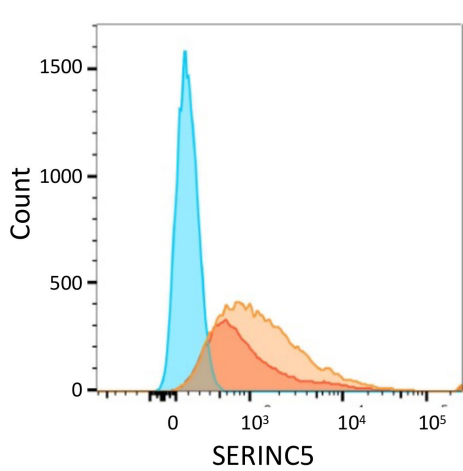

B

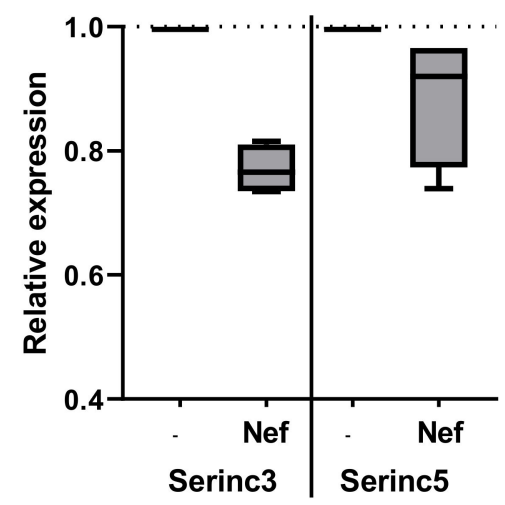

C

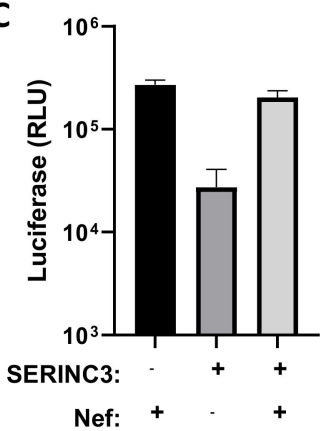

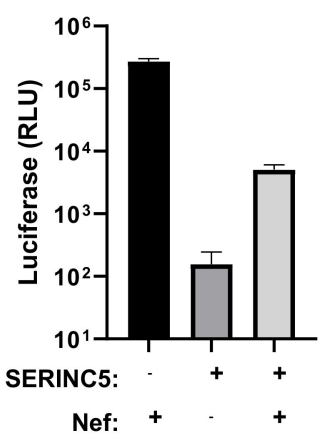

D

Figure 2. (A) Downregulation of serine incorporator 3 (SERINC3) and SERINC5 membrane expression by HIV-1 Nef. HEK293T cells were co-transfected with plasmids expressing Nef and SERINC3 or SERINC5 or in combination with a relevant empty vector. The surface expression of SERINC3 and SERINC5 (orange) or in combination with HIV-1 Nef (red) was determined by flow cytometry as the geometric mean of fluorescent intensity. Background fluorescent (blue) control was included. (B) Downregulation of SERINC3 and SERINC5 by Nef as shown as relative expression as compared to the control of four independent experiments $(p<0.05)$. (C) The effect of SERINC3 (left panel) and SERINC5 (right panel) on HIV-1 infectivity: Infectivity of Bal26-pseudotyped HIV-1 produced in 293T cells overexpressing Nef (black bar), SERINC3 or SERINC5 (dark gray bar) and SERINC3 or SERINC5 in combination with Nef (light gray bar) in U87 CD4+CCR5+. Infectivity was determined by luciferase activity in relative light units (RLU). Mean \pm SD are shown. (D) Expression of Nef from pcDNA3.1 encoding primary Nef proteins and $\beta$-actin levels were determined by Western blotting.

We selected 20 primary Nef proteins from individuals with HIV-1 participating in the Amsterdam Cohort Studies that show amino acid variation in the AP-2 binding site, the ExxxLL motif, changes in the number of positively charged amino acids and length of the protein interaction site consisting of the amino acid residues 12-39 (AA 12-39) and contain the previously identified amino acid polymorphisms [14,25,26] (Figure 3). The primary Nef proteins were cloned into expression plasmids and Nef expression by these constructs was demonstrated by Western blotting (Figure 2D). The effect of naturally occurring mutations in patient Nef proteins on SERINC3- and SERINC5-restricted HIV-1 
infectivity (Bal26-pseudotyped single-round luciferase reporter virus) was determined in U87 CD4+CCR5+ cells.
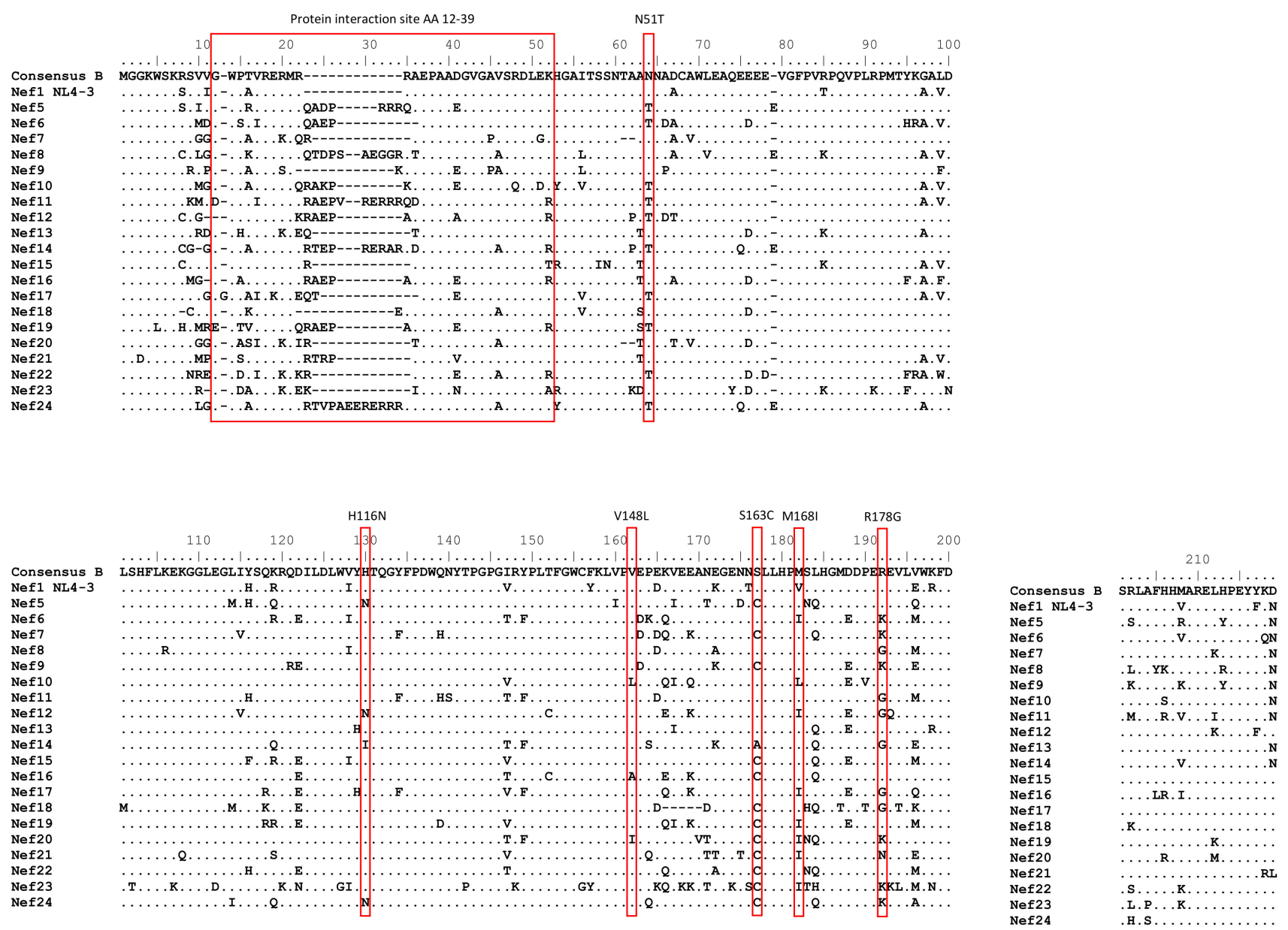

Figure 3. Amino acid variation in Nef proteins obtained from individuals with HIV-1. HIV-1 consensus B Nef, NL4-3 Nef (Nef1) and Nef proteins from patients with HIV-1 (Nef5-24). Red boxes indicate some of the previously described amino acid polymorphisms $[14,25,26]$ and binding sites for reference.

We showed that the infectivity of Bal26-pseudotyped HIV-1 produced in the presence of primary Nef proteins in combination with SERINC3 or SERINC5 displayed considerable variation in infectivity (Figure 4), but the majority of the primary Nef proteins showed increased Nef activity as compared to wild-type HIV-1 NL4-3 Nef (Nef1). A significant increase in infectivity of HIV-1 produced in the presence of SERINC3 was observed for Nef5, Nef6, Nef7 and Nef24 (Figure 4A), and a trend was observed for Nef9, Nef14, Nef15, Nef16, Nef17, Nef18 and Nef22 (Figure 4B). Nef18 was able to significantly increase the infectivity of HIV-1 in the presence of SERINC5 (Figure 4B), and a trend was observed for Nef5, Nef7, Nef15, Nef17, Nef21, Nef22, Nef23 and Nef24 (Figure 4B). For a selection of primary Nef proteins, an additional flowcytometry analysis was performed to demonstrate downregulation of SERINC5 membrane expression. An increased ability of SERINC5 downregulation was observed for the primary Nef proteins in comparison to Nef1 (Figure 4C), which is in agreement with the increased infectivity of HIV-1 produced in the presence of SERINC5 and primary Nef. Moreover, a significant correlation of the activity of primary Nef proteins to counteract SERINC3 and SERINC5 was observed $\left(R^{2}=0.61 ; p=0.002\right)$ (Figure 4D). 
A

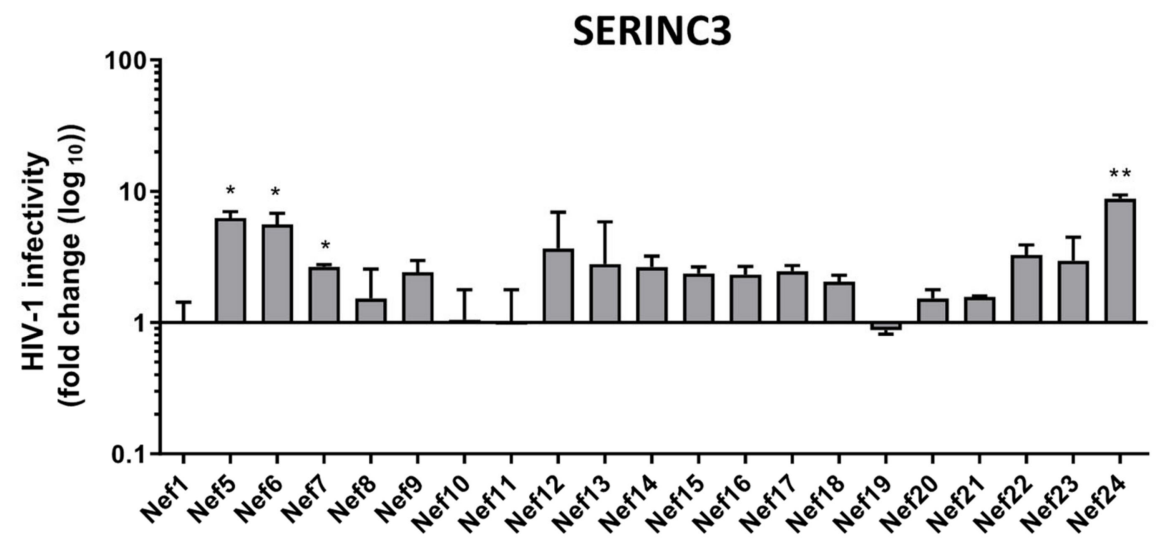

B
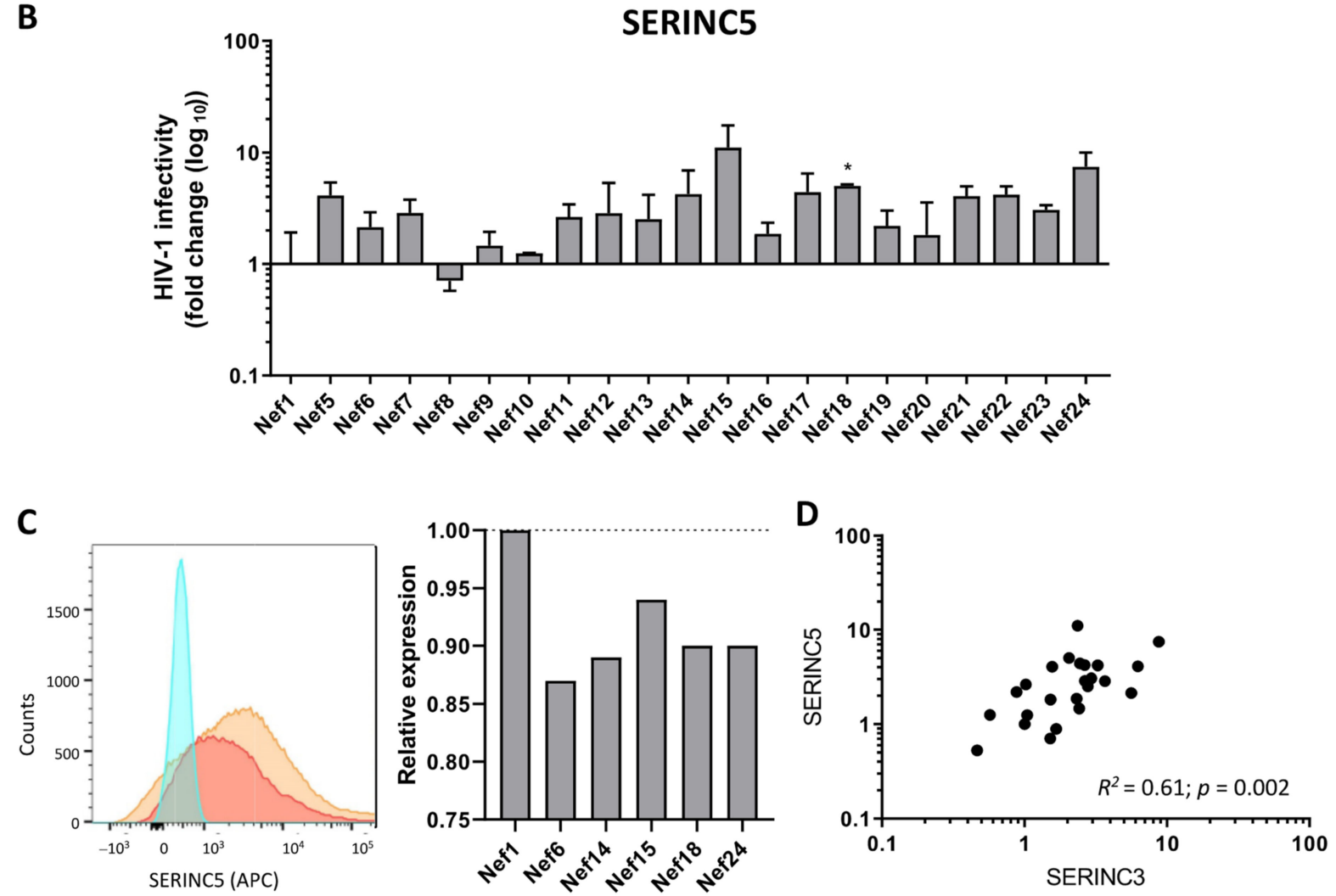

Figure 4. Effect of naturally occurring amino acid variations on infectivity of Bal26-pseudotyped HIV-1. Infectivity of Bal26 Nef-deficient single-round luciferase reporter virus produced in 293T cells overexpressing SERINC3 (A) or SERINC5 (B) in the presence of wild-type NL4-3 Nef (Nef1) or Nef proteins obtained from individuals with HIV-1 (Nef5-Nef24). The infectivity of the virus produced in the presence of the Nef and SERINC3/5 was corrected for the infectivity of the virus produced in the presence of the same primary Nef and an empty vector. Virus infectivity is expressed relative to the virus produced in the presence of NL4-3 Nef (fold change). Means \pm SD of three independent experiments are shown. Unpaired two-tailed $t$-test $\left.{ }^{*} p<0.05 ;{ }^{* *} p<0.01\right)$. (C) Downregulation of SERINC5 membrane expression by primary Nef proteins was determined by flow cytometry (Left panel—orange: Nef1; red: Nef24; blue: background fluorescent control). Downregulation of SERINC5 membrane expression by primary Nef (Nef6, 14, 15, 18, and 24) relative to NL4-3 Nef (Nef1) (right panel). (D) Correlation between the ability of the primary Nef proteins to counteract SERINC3 and SERINC5. 


\subsection{Association between Naturally Occurring Mutations in Nef and the Ability to Counteract SERINC3 and SERINC5}

Next, we determined whether changes in the length and charge of the protein interaction site and naturally occurring Nef mutations were associated with changes in Nef activity to counteract SERINC3 and SERINC5 (Figure 5; all data are shown in Supplementary Table S2). Previous reports indicated that some naturally occurring mutations in Nef could affect both SERINC3 and SERINC5 (N51T, H116N, V148L/X, 161N and M168I/X), while others only affected SERINC3 (8R, 9S, 11P, 12G, 14A, 15A, 21K, 28E, 43I, 182E and $188 \mathrm{~S})$ or SERINC5 (14S, 21R, 54D, 63E, 81F, 120F, 157N and 158K) [14,25,26]. The change of charge in the protein interaction site (AA 12-39) and the presence of amino acids 12G, N51T, H116N and 188S in Nef were associated with a significant increased infectivity of Bal26-pseudotyped HIV-1 produced in the presence of SERINC3, while increased length of the protein interaction site (AA12-39), 9S, 43I and S163C also increased and 11P, 14A, V148X, 161N and R178G decreased infectivity, albeit not significantly (Figure 5A and Supplementary Table S2). A change of charge in the protein interaction site (AA 12-39) and the S163C mutation in the ExxxLL binding motif of Nef increased, whereas the loss of valine at position 148 (V148X) decreased, the HIV-1 infectivity of Bal26-pseudotyped HIV-1 produced in the presence of SERINC5 (Figure 5B and Supplementary Table S2). Nef variants containing $21 \mathrm{R}$ and $\mathrm{H} 116 \mathrm{~N}$ also increased infectivity, whereas the variant R178G decreased infectivity, albeit not significantly (Figure 5B and Supplementary Table S2).

A
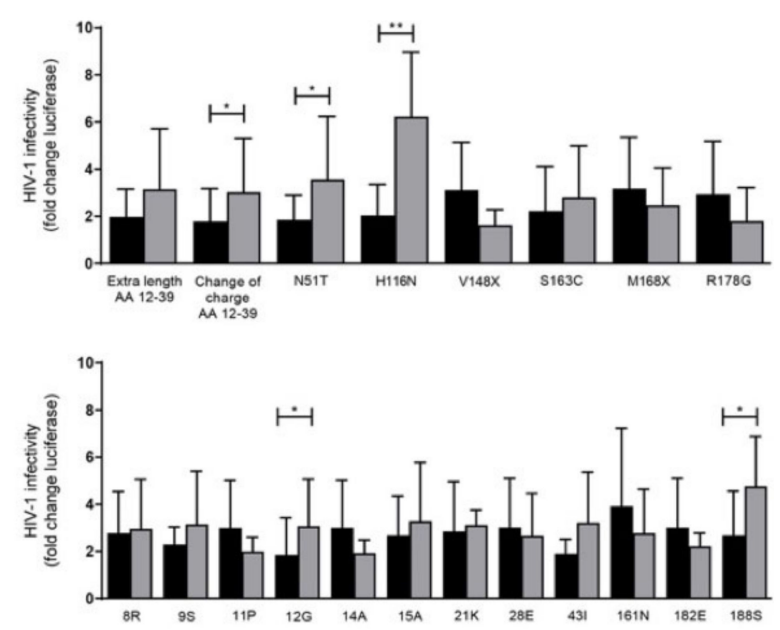

B
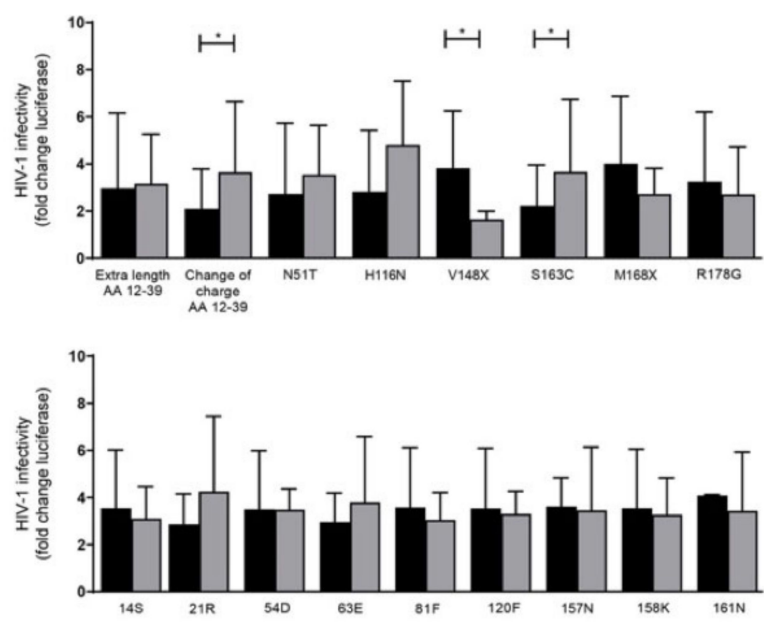

Figure 5. Effect of naturally occurring mutations in Nef on HIV-1 infectivity. The ability of primary Nef proteins that do or do not contain the indicated amino acids or mutations to counteract (A) SERINC3- or (B) SERINC5-mediated HIV-1 restriction was compared. Virus infectivity is expressed relative to the virus produced in the presence of NL4-3 Nef (fold change of three independent experiments). Means \pm SD of Nef proteins containing the indicated amino acid or mutation are given. Mann-Whitney $\mathrm{U}$ test $\left({ }^{*} p<0.05 ;{ }^{* *} p<0.01\right)$. Black bar: indicated amino acid or mutation is absent; grey bar: indicated amino acid or mutation is present.

\subsection{Effect of Naturally Occurring Mutations in Nef on Disease Progression}

The effect of the naturally occurring mutations in Nef on HIV-1 disease progression was determined by Kaplan-Meier and Cox proportional hazard survival analyses using AIDS according to the 1993 CDC definition or AIDS-related death (Figure 6 and Supplementary Table S3) as endpoints. We observed that individuals with HIV-1 containing the 8R, 157N or R178G polymorphism in Nef showed an accelerated disease progression. Individuals with an HIV-1 variant containing arginine at position 8 (8R) in Nef progressed after AIDS (log rank, $p=0.017$; relative hazard (RH), 1.66; 95\% CI, 1.09-2.55; $p=0.018$ ), asparagine at position $157(157 \mathrm{~N})$ in Nef died earlier from AIDS-related disease (log rank, 
$p=0.041 ; \mathrm{RH}, 2.52 ; 95 \% \mathrm{CI}, 1.00-6.31 ; p=0.048)$ and the R178G Nef mutation showed faster progression to AIDS (log rank, $p=0.026$; $\mathrm{RH}, 1.78 ; 95 \% \mathrm{CI}, 1.06-2.97 ; p=0.037)$ and AIDS-related death ( $\log$ rank, $p=0.040 ; \mathrm{RH}, 1.84 ; 95 \%$ CI, 1.00-3.37; $p=0.048$ ) (Figure 6 and Supplementary Table S3).

A

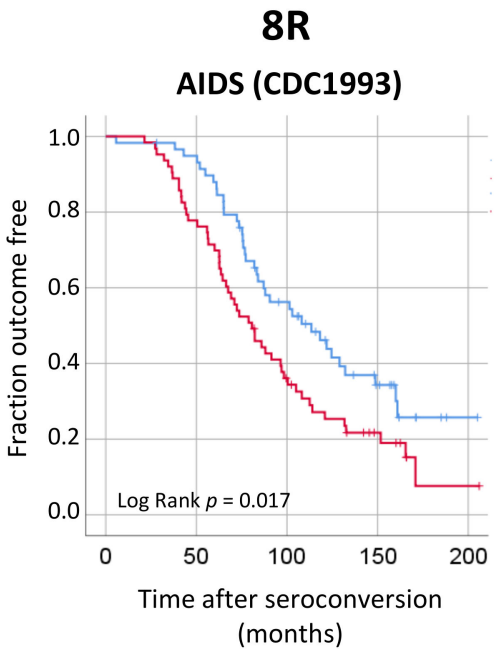

AIDS related death

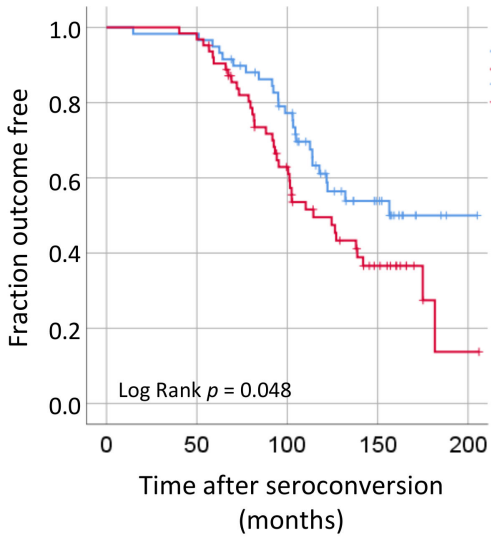

B

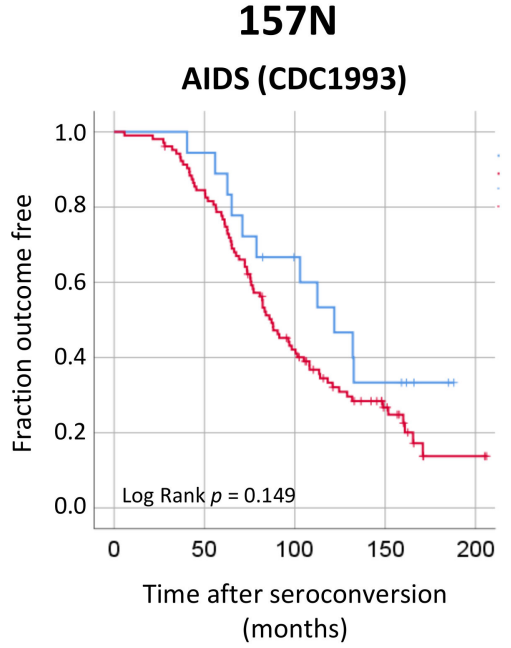

AIDS related death

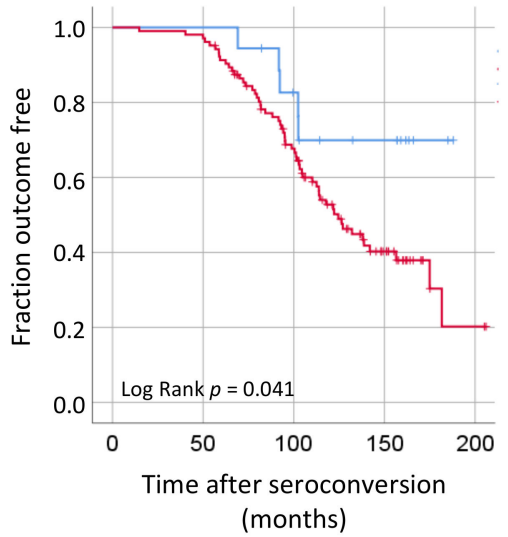

C
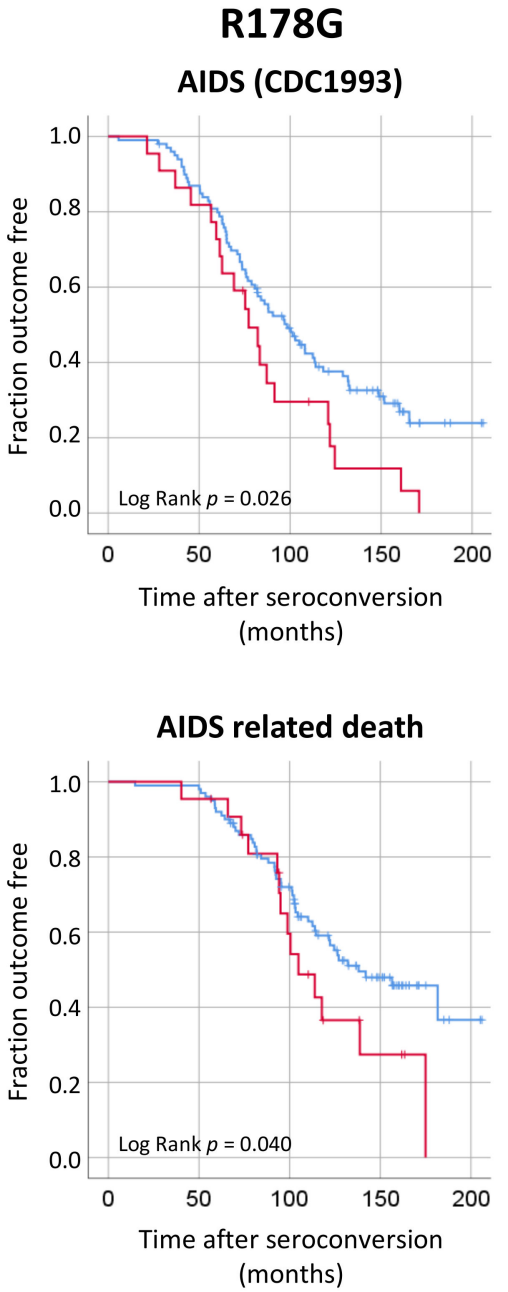

amino acid or mutation absent

amino acid or mutation present

Figure 6. Effect of naturally occurring mutations in Nef on disease progression. Kaplan-Meier survival analysis for amino acid variations or mutations 8R (A), 157N (B) and R178G (C) in Nef with time in months from seroconversion to progression to AIDS as defined by the CDC definition 1993 (top panel) or AIDS-related death (bottom panel). $P$ values displayed represent log-rank test.

\section{Discussion}

Nef is a multifunctional viral protein that has the ability to downregulate cell surface molecules, including CD4, MHC-I and T-cell receptor [1], allowing HIV-1 to evade ADCC and CTLs [2-5]. Nef can also alter the activation state of T cells and macrophages and perturbs the actin cytoskeleton by engaging with cellular kinases [6-8]. In the present study, we evaluated the effect of naturally occurring mutations in HIV-1 Nef on its ability to counteract SERINC3 and SERINC5 restriction and disease progression. Our analysis showed that, in agreement with previous studies HIV-1, Nef was able to counteract the restriction of SERINC3 and SERINC5 in vitro and thereby enhanced HIV-1 infectivity. We observed high variability in the primary Nef amino acid sequences and also demonstrated variability in their ability to downregulate SERINC3 as well as SERINC5. Most Nef proteins 
showed an increased activity to counteract SERINC3 and SERINC5 as compared to NL4-3 Nef, indicating an important role for Nef in vivo.

Different regions and amino acid polymorphisms in the Nef protein have been described to affect the ability to counteract SERINC3- and SERINC5-mediated downregulation. Residues 12 to 39, which are located in the N-terminal, largely unfolded anchor domain of Nef, were recently implicated in a wide range of Nef activities. The residues were originally described to recruit the Nef-associated kinase complex (NAKC) to facilitate HIV-1 replication in primary target cells $[7,27]$ and enhance the secretion of extracellular vesicles containing Nef and proinflammatory cytokines [28,29]. Interestingly, it was shown that deletions in this protein interaction site of HIV- $1_{\mathrm{SF} 2}$ Nef prevent the downregulation of CD4 and MHC-I and the antagonism of SERINC5 [30,31]. Moreover, this protein interaction site contains the amino acid stretch RxRxRR on position 17-22, which was shown to be involved in the anchoring of Nef to the membrane and exosome release [32-35]. In primary HIV-1 variants, we observed variation in the length and the number of positively charged amino acids in this region (protein interaction site). Our in vitro analysis showed that the change in the number of positively charged amino acids in this region was associated with increased ability of Nef to counteract SERINC3 and SERINC5. However, no effect of the charge changes was observed on HIV-1 disease progression. Several specific amino acids located in and near the protein interaction site in Nef have been described to affect the ability of Nef to downregulate SERINC3/5 [26]. We observed that glycine at position 12 and serine at position 188 of Nef were associated with increased infectivity, indicating an increased ability to downregulate SERINC3 and confirming previous observations [26]. However, the effect of the other mutations in this region or in close proximity (AA8-43) on either SERINC3 and/or SERINC5 downregulation could not be confirmed. This can most likely be explained by the high variability (including length and charge) of the protein interaction site in Nef obtained from primary HIV-1 variants, possibly containing additional mutations compensating for the loss or gain of Nef function. Arginine at position 8 in this region was shown to have an effect on disease progression. The $8 \mathrm{R}$ has previously been associated with loss of the ability to internalize SERINC3 in subtype A, C and D HIV-1 and, in combination with glycine at position 11, poor activity to internalize SERINC3 in subtype B HIV-1; however, 8R had no effect on SERINC5, CD4 and MHC class I downregulation [26]. In our cohort, this amino acid was present in $52 \%$ of the individuals with HIV-1 and was shown to be associated with an accelerated disease progression, which cannot be explained by a loss of the ability to counteract SERINC3 and indicates that this amino acid has another effect in vivo and, for instance, allows immune escape from cytotoxic $\mathrm{T}$ cells or compensates for other attenuating (escape) mutations.

Nef confiscates the endocytic and late secretory pathways through the modulation of adapter and accessory proteins involved in vesicle formation, such as the AP complexes and dynamin [4,36-38]. Nef interrupts MHC-I trafficking by binding to MHC-I in the endoplasmic reticulum or early Golgi, after which the AP-1 protein is recruited in the trans-Golgi network (Nef:MHC-I:AP-1 tripartite complex) [39-48]. AP-1 directs MHC-I, subsequently, into the endo-lysosomal pathway $[43,44,49]$. In contrast, CD4 trafficking is not inhibited by Nef. Instead, Nef internalizes CD4 at the plasma membrane [49-53]. The downregulation of CD4 by Nef was shown to require AP-2 (Nef:AP-2:CD4 ternary complex). This ternary complex at the plasma membrane has been proposed to promote clathrin-dependent endocytosis [54-56]. In addition, the AP-1 protein was shown to be involved in Nef-dependent CD28 downregulation [57]; however, an earlier study also demonstrated involvement of the AP-2 protein [58]. Downregulation of SERINC3/5 by Nef is also thought to require clathrin and AP-2 to redistribute these proteins to the endosomes $[9,10,59]$.

Nef has conserved sequences, such as dileucine motifs (ExxxLL; Figure 1), the diacidic motif (DD174-175) and the three charged C-terminal residues (ERE177; Figure 1) in the C-loop to interact or to help establish an interaction with the endocytic machinery, mainly AP-1 and AP-2 proteins $[15,16,50,60-62]$. These motifs are necessary for the downregulation 
of CD4 and, in the case of the ExxxLL motif, also MHC-I [4,15]. In addition, Nef requires these dileucine and diacidic motifs to counteract SERINC5 activity by sending it to the endosomes [31]. It was shown that although Nef is one of the most variable proteins amongst primate lentiviruses, the dileucine motif is highly conserved between species because it is required to abolish SERINC5 activity [31,63]. Previously, an amino acid polymorphism (S163) in the ExxxLL region was associated with the ability of Nef to downregulate CD4 [64]. We observed that this polymorphism (S163C) was present in 39.8\% of the primary HIV-1 variants tested and was associated with increased Nef activity to counteract SERINC5 and, consequently, with higher HIV-1 infectivity. This is in agreement with an earlier study by Jin et al. demonstrating higher activity against SERINC5 of Nef containing cysteine at position 163 [14]. The 157N is located near the ExxxLL region and has previously been demonstrated to have a slightly decreased ability to internalize SERINC5 as compared to Nef that does not have asparagine at this position [26]. Although we did not observe an effect of this mutation in the context of primary Nef variants on infectivity of HIV-1 produced in the presence of SERINC3 and SERINC5, the asparagine at position 157 in Nef was associated with faster disease progression. This may indicate that this mutation is associated with escape from the immune system and, thus, contributes to disease progression.

The R178G polymorphism located in the ERE177 region was observed in almost 18\% of the primary isolates. Our in vitro analysis showed that this mutation lowered HIV-1 infectivity, albeit not significantly, indicating a possible loss of the ability of these Nef proteins to counteract SERINC3 and SERINC5. Interestingly, the presence of the R178G mutation in Nef was associated with accelerated progression to AIDS and AIDS-related death in our cohort. The lower ability of the R178G mutation to counteract SERINC3 and -5 may indicate that, during the course of infection, the selective pressure of this restriction protein is lost in these individuals, explaining the selective outgrowth of HIV-1 variants containing the R178G mutation in Nef. A recent study delivered strong evidence for the role of R178 in AP-2 recruitment, showing direct interaction of this amino acid with a pocket formed by the AP-2 $\alpha: \sigma 2$ subunit hemicomplex [16,65], and therefore, this mutation may indeed affect the ability of Nef to counteract SERINC3 and -5. Indeed, the mutation of the three charged C-terminal residues in the C-loop of Nef (ERE177AAA), including R178, abrogated the function of Nef to counteract SERINC5 [63], which confirms our in vitro observation. However, the charged residues ERE177 were also found to be crucial for CD4 downmodulation, but not for MHC-I downmodulation, and enhanced HIV-1 infectivity $[15,16,42]$. A recent study also showed that the G176R mutation in Nef selectively disrupts CD4 downregulation, but not SERINC 5 antagonism by Nef, likely by disruption of the AP-2 binding and the uncoupling of these two functions of Nef [62]. These data could also indicate that the observed accelerated disease progression associated with the R178G mutation may be related to the loss of the ability of Nef to downregulate CD4. Downregulation of CD4 is thought to be important for HIV-1 replication and pathogenesis because it prevents the premature death of HIV-1-infected cells by coinfection or the induction of apoptosis via CD4 signaling [66-70]. Therefore, the accelerated disease progression may also be explained by an increased loss of infected CD4 cells, especially in the gut-associated lymphoid tissues where a high number of infected CD4 cells reside [71], which, consequently, may result in increased bacterial translocation and high immune activation [72,73].

Several other amino acid polymorphisms in Nef have been identified to play a role in SERINC3 or SERINC5 antagonism $[14,25,26]$. In our study, we did not find a significant effect of most of these mutations on Nef activity against SERINC3 or SERINC5. However, we did observe that the N51T, H116N and 188S mutations increased HIV-1 infectivity when the virus was produced in the presence of SERINC3. The H116N mutation has been reported to have a negative effect on infectivity in the presence of SERINC5 but had no effect on SERINC3 internalization [14,26], contradicting our observations. However, no effect of the H116N mutation in Nef on disease progression was observed, indicating that 
the change in functionality associated with this polymorphism is not essential or is too small to affect HIV-1 replication in vivo. Serine at position 188 has previously been described with increased SERINC3 internalization function [26], confirming our observations, while the N51T mutation has only been associated with a modest increased functionality to internalize SERINC5 [14]. In agreement with our observation, the loss of valine at position 148 has been associated with the loss of the ability to counteract SERINC5 [14] and lower infectivity. However, no effect of these mutations on disease progression was observed.

Here, we observed that amino acid changes in primary Nef affect the ability of this protein to counteract SERINC3- and SERINC5-mediated HIV-1 restriction. However, these mutations, except for 8R, 157N and R178G, have no significant effect on HIV-1 pathogenesis. Nef activity was determined in vitro in the presence of SERINC3 and SERINC5 overexpression, and this may not be reflective of Nef function in vivo where SERINC3 and SERINC5 expression may be lower and Nef proteins with lower in vitro antagonizing activity might still be able to sufficiently maintain viral infectivity. It is, therefore, likely that the Nef function to counteract SERINC3 and SERINC5 is maintained during viral evolution in vivo, similar to its ability to downregulate CD4 and MHC class I.

Supplementary Materials: The following are available online at https:/ /www.mdpi.com/1999-4 915/13/3/423/s1, Table S1: Amino acid variations in Nef proteins obtained from individuals with HIV-1; Table S2: Mean HIV-1 infectivity in the presence of SERINC3/5 in the absence or presence of naturally occurring mutations in Nef; Table S3: Cox Regression analysis for progression to AIDS and AIDS-related death.

Author Contributions: Conceptualization, Z.K., T.B. and N.A.K.; methodology, Z.K., T.B. and N.A.K.; validation, Z.K. and A.C.v.N.; formal analysis, Z.K., T.B. and N.A.K.; investigation, Z.K., A.C.v.N., A.F.G., S.W.v.W. and K.A.v.D.; resources, N.A.K.; writing —original draft preparation, Z.K.; writingreview and editing, Z.K. and N.A.K.; visualization, Z.K.; supervision, N.A.K.; project administration, Z.K.; funding acquisition, N.A.K. All authors have read and agreed to the published version of the manuscript.

Funding: This research was funded by Aidsfonds (2004062) and the Landsteiner Foundation Blood Research (0526).

Institutional Review Board Statement: The study was conducted according to the guidelines of the Declaration of Helsinki, and approved by the Institutional Review Board of the Amsterdam Medical Center (MEC 07/182, 20 August 2007).

Informed Consent Statement: Informed consent was obtained from all subjects involved in the study.

Data Availability Statement: The data presented in this study are available in the article and supplementary material.

Acknowledgments: We thank all participants of the Amsterdam Cohort Studies for their contribution. The Amsterdam Cohort Studies on HIV infection and AIDS, a collaboration between the Public Health Service Amsterdam, the Amsterdam UMC of the University of Amsterdam, Sanquin Blood Supply Foundation, Medical Center Jan van Goyen and the HIV Focus Center of the DC-Clinics, are part of the Netherlands HIV Monitoring Foundation and financially supported by the Center for Infectious Disease Control of the Netherlands National Institute for Public Health and the Environment.

Conflicts of Interest: The authors declare no conflict of interest. The funders had no role in the design of the study; in the collection, analyses, or interpretation of data; in the writing of the manuscript, or in the decision to publish the results.

\section{References}

1. Landi, A.; Iannucci, V.; Nuffel, A.V.; Meuwissen, P.; Verhasselt, B. One protein to rule them all: Modulation of cell surface receptors and molecules by HIV Nef. Curr. HIV Res. 2011, 9, 496-504. [CrossRef]

2. Alsahafi, N.; Ding, S.; Richard, J.; Markle, T.; Brassard, N.; Walker, B.; Lewis, G.K.; Kaufmann, D.E.; Brockman, M.A.; Finzi, A. Nef proteins from HIV-1 elite controllers are inefficient at preventing antibody-dependent cellular cytotoxicity. J. Virol. 2015, 90, 2993-3002. [CrossRef] 
3. Collins, K.L.; Chen, B.K.; Kalams, S.A.; Walker, B.D.; Baltimore, D. HIV-1 Nef protein protects infected primary cells against killing by cytotoxic T lymphocytes. Nature 1998, 391, 397-401. [CrossRef]

4. Le Gall, S.; Erdtmann, L.; Benichou, S.; Berlioz-Torrent, C.; Liu, L.; Benarous, R.; Heard, J.M.; Schwartz, O. Nef interacts with the mu subunit of clathrin adaptor complexes and reveals a cryptic sorting signal in MHC I molecules. Immunity 1998, 8, 483-495. [CrossRef]

5. Veillette, M.; Coutu, M.; Richard, J.; Batraville, L.A.; Dagher, O.; Bernard, N.; Tremblay, C.; Kaufmann, D.E.; Roger, M.; Finzi, A. The HIV-1 GP120 CD4-bound conformation is preferentially targeted by antibody-dependent cellular cytotoxicity-mediating antibodies in sera from HIV-1-infected individuals. J. Virol. 2015, 89, 545-551. [CrossRef] [PubMed]

6. Alexander, L.; Du, Z.; Rosenzweig, M.; Jung, J.U.; Desrosiers, R.C. A role for natural simian immunodeficiency virus and human immunodeficiency virus type 1 nef alleles in lymphocyte activation. J. Virol. 1997, 71, 6094-6099. [CrossRef] [PubMed]

7. Baur, A.S.; Sass, G.; Laffert, B.; Willbold, D.; Cheng-Mayer, C.; Peterlin, B.M. The N-terminus of Nef from HIV-1/SIV associates with a protein complex containing Lck and a serine kinase. Immunity 1997, 6, 283-291. [CrossRef]

8. Stolp, B.; Reichman-Fried, M.; Abraham, L.; Pan, X.; Giese, S.I.; Hannemann, S.; Goulimari, P.; Raz, E.; Grosse, R.; Fackler, O.T. HIV-1 Nef interferes with host cell motility by deregulation of Cofilin. Cell Host Microbe 2009, 6, 174-186. [CrossRef]

9. Rosa, A.; Chande, A.; Ziglio, S.; De Sanctis, V.; Bertorelli, R.; Goh, S.L.; McCauley, S.M.; Nowosielska, A.; Antonarakis, S.E.; Luban, J.; et al. HIV-1 Nef promotes infection by excluding SERINC5 from virion incorporation. Nature 2015, 526, 212-217. [CrossRef]

10. Usami, Y.; Wu, Y.; Gottlinger, H.G. SERINC3 and SERINC5 restrict HIV-1 infectivity and are counteracted by Nef. Nature 2015, 526, 218-223. [CrossRef]

11. Sood, C.; Marin, M.; Chande, A.; Pizzato, M.; Melikyan, G.B. SERINC5 protein inhibits HIV-1 fusion pore formation by promoting functional inactivation of envelope glycoproteins. J. Biol. Chem. 2017, 292, 6014-6026. [CrossRef]

12. Shi, J.; Xiong, R.; Zhou, T.; Su, P.; Zhang, X.; Qiu, X.; Li, H.; Li, S.; Yu, C.; Wang, B.; et al. HIV-1 Nef Antagonizes SERINC5 Restriction by downregulation of SERINC5 via the endosome/lysosome system. J. Virol. 2018, 92, e00196. [CrossRef]

13. Foster, J.L.; Denial, S.J.; Temple, B.R.; Garcia, J.V. Mechanisms of HIV-1 Nef function and intracellular signaling. J. Neuroimmune Pharmacol. 2011, 6, 230-246. [CrossRef]

14. Jin, S.W.; Alsahafi, N.; Kuang, X.T.; Swann, S.A.; Toyoda, M.; Gottlinger, H.; Walker, B.D.; Ueno, T.; Finzi, A.; Brumme, Z.L.; et al. Natural HIV-1 nef polymorphisms impair SERINC5 downregulation activity. Cell Rep. 2019, 29, 1449-1457.e45. [CrossRef] [PubMed]

15. Sauter, D.; Hotter, D.; Van Driessche, B.; Sturzel, C.M.; Kluge, S.F.; Wildum, S.; Yu, H.; Baumann, B.; Wirth, T.; Plantier, J.C.; et al. Differential regulation of NF-kappaB-mediated proviral and antiviral host gene expression by primate lentiviral Nef and Vpu proteins. Cell Rep. 2015, 10, 586-599. [CrossRef]

16. Lindwasser, O.W.; Smith, W.J.; Chaudhuri, R.; Yang, P.; Hurley, J.H.; Bonifacino, J.S. A diacidic motif in human immunodeficiency virus type $1 \mathrm{Nef}$ is a novel determinant of binding to AP-2. J. Virol. 2008, 82, 1166-1174. [CrossRef]

17. Kootstra, N.A.; Navis, M.; Beugeling, C.; van Dort, K.A.; Schuitemaker, H. The presence of the Trim5alpha escape mutation H87Q in the capsid of late stage HIV-1 variants is preceded by a prolonged asymptomatic infection phase. AIDS 2007, 21, 2015-2023. [CrossRef]

18. Schuitemaker, H.; Koot, M.; Kootstra, N.A.; Dercksen, M.W.; de Goede, R.E.; van Steenwijk, R.P.; Lange, J.M.; Schattenkerk, J.K.; Miedema, F.; Tersmette, M. Biological phenotype of human immunodeficiency virus type 1 clones at different stages of infection: Progression of disease is associated with a shift from monocytotropic to T-cell-tropic virus population. J. Virol. 1992, 66, 1354-1360. [CrossRef]

19. Bjorndal, A.; Deng, H.; Jansson, M.; Fiore, J.R.; Colognesi, C.; Karlsson, A.; Albert, J.; Scarlatti, G.; Littman, D.R.; Fenyo, E.M. Coreceptor usage of primary human immunodeficiency virus type 1 isolates varies according to biological phenotype. J. Virol. 1997, 71, 7478-7487. [CrossRef]

20. Chen, B.K.; Saksela, K.; Andino, R.; Baltimore, D. Distinct modes of human immunodeficiency virus type 1 proviral latency revealed by superinfection of nonproductively infected cell lines with recombinant luciferase-encoding viruses. J. Virol. 1994, 68, 654-660. [CrossRef]

21. Connor, R.I.; Chen, B.K.; Choe, S.; Landau, N.R. Vpr is required for efficient replication of human immunodeficiency virus type-1 in mononuclear phagocytes. Virology 1995, 206, 935-944. [CrossRef]

22. He, J.; Choe, S.; Walker, R.; Di Marzio, P.; Morgan, D.O.; Landau, N.R. Human immunodeficiency virus type 1 viral protein R (VPR) arrests cells in the G2 phase of the cell cycle by inhibiting P34cdc2 activity. J. Virol. 1995, 69, 6705-6711. [CrossRef]

23. Tersmette, M.; Winkel, I.N.; Groenink, M.; Gruters, R.A.; Spence, R.P.; Saman, E.; Van Der Groen, G.; Miedema, F.; Huisman, J.G. Detection and subtyping of HIV-1 isolates with a panel of characterized monoclonal antibodies to HIV p24gag. Virology 1989, 171, 149-155. [CrossRef]

24. Ananth, S.; Morath, K.; Trautz, B.; Tibroni, N.; Shytaj, I.L.; Obermaier, B.; Stolp, B.; Lusic, M.; Fackler, O.T. Multifunctional roles of the N-terminal region of HIV-1SF2Nef are mediated by three independent protein interaction sites. J. Virol. 2019, 94, e01398. [CrossRef]

25. Sudderuddin, H.; Kinloch, N.N.; Jin, S.W.; Miller, R.L.; Jones, B.R.; Brumme, C.J.; Joy, J.B.; Brockman, M.A.; Brumme, Z.L. Longitudinal within-host evolution of HIV Nef-mediated CD4, HLA and SERINC5 downregulation activity: A case study. Retrovirology 2020, 17, 3. [CrossRef] 
26. Jin, S.W.; Mwimanzi, F.M.; Mann, J.K.; Bwana, M.B.; Lee, G.Q.; Brumme, C.J.; Hunt, P.W.; Martin, J.N.; Bangsberg, D.R.; Ndung'u, T.; et al. Variation in HIV-1 Nef function within and among viral subtypes reveals genetically separable antagonism of SERINC3 and SERINC5. PLoS Pathog. 2020, 16, e1008813. [CrossRef]

27. Homann, S.; Tibroni, N.; Baumann, I.; Sertel, S.; Keppler, O.T.; Fackler, O.T. Determinants in HIV-1 Nef for enhancement of virus replication and depletion of $\mathrm{CD}^{+} \mathrm{T}$ lymphocytes in human lymphoid tissue ex vivo. Retrovirology 2009, 6, 6. [CrossRef]

28. Lee, J.H.; Schierer, S.; Blume, K.; Dindorf, J.; Wittki, S.; Xiang, W.; Ostalecki, C.; Koliha, N.; Wild, S.; Schuler, G.; et al. HIV-Nef and ADAM17-containing plasma extracellular vesicles induce and correlate with immune pathogenesis in chronic HIV infection. EBioMedicine 2016, 6, 103-113. [CrossRef]

29. Ostalecki, C.; Wittki, S.; Lee, J.H.; Geist, M.M.; Tibroni, N.; Harrer, T.; Schuler, G.; Fackler, O.T.; Baur, A.S. HIV Nef- and Notch1-dependent endocytosis of ADAM17 induces vesicular TNF secretion in chronic HIV infection. EBioMedicine 2016, 13, 294-304. [CrossRef]

30. Fackler, O.T.; Moris, A.; Tibroni, N.; Giese, S.I.; Glass, B.; Schwartz, O.; Krausslich, H.G. Functional characterization of HIV-1 Nef mutants in the context of viral infection. Virology 2006, 351, 322-339. [CrossRef]

31. Trautz, B.; Pierini, V.; Wombacher, R.; Stolp, B.; Chase, A.J.; Pizzato, M.; Fackler, O.T. The antagonism of HIV-1 Nef to SERINC5 particle infectivity restriction involves the counteraction of virion-associated pools of the restriction factor. J. Virol. 2016, 90, 10915-10927. [CrossRef] [PubMed]

32. Ali, S.A.; Huang, M.B.; Campbell, P.E.; Roth, W.W.; Campbell, T.; Khan, M.; Newman, G.; Villinger, F.; Powell, M.D.; Bond, V.C Genetic characterization of HIV type 1 Nef-induced vesicle secretion. AIDS Res. Hum. Retroviruses 2010, 26, 173-192. [CrossRef]

33. Bentham, M.; Mazaleyrat, S.; Harris, M. Role of myristoylation and N-terminal basic residues in membrane association of the human immunodeficiency virus type 1 Nef protein. J. Gen. Virol. 2006, 87, 563-571. [CrossRef]

34. Welker, R.; Harris, M.; Cardel, B.; Krausslich, H.G. Virion incorporation of human immunodeficiency virus type 1 Nef is mediated by a bipartite membrane-targeting signal: Analysis of its role in enhancement of viral infectivity. J. Virol. 1998, 72, 8833-8840. [CrossRef]

35. Cruz, N.V.; Amorim, R.; Oliveira, F.E.; Speranza, F.A.; Costa, L.J. Mutations in the nef and vif genes associated with progression to AIDS in elite controller and slow-progressor patients. J. Med. Virol. 2013, 85, 563-574. [CrossRef] [PubMed]

36. Burtey, A.; Rappoport, J.Z.; Bouchet, J.; Basmaciogullari, S.; Guatelli, J.; Simon, S.M.; Benichou, S.; Benmerah, A. Dynamic interaction of HIV-1 Nef with the clathrin-mediated endocytic pathway at the plasma membrane. Traffic 2007, 8, 61-76. [CrossRef]

37. Johannes, L.; Pezo, V.; Mallard, F.; Tenza, D.; Wiltz, A.; Saint-Pol, A.; Helft, J.; Antony, C.; Benaroch, P. Effects of HIV-1 Nef on retrograde transport from the plasma membrane to the endoplasmic reticulum. Traffic 2003, 4, 323-332. [CrossRef]

38. Pizzato, M.; Helander, A.; Popova, E.; Calistri, A.; Zamborlini, A.; Palu, G.; Gottlinger, H.G. Dynamin 2 is required for the enhancement of HIV-1 infectivity by Nef. Proc. Natl. Acad. Sci. USA 2007, 104, 6812-6817. [CrossRef]

39. Noviello, C.M.; Benichou, S.; Guatelli, J.C. Cooperative binding of the class I major histocompatibility complex cytoplasmic domain and human immunodeficiency virus type 1 Nef to the endosomal AP-1 complex via its mu subunit. J. Virol. 2008, 82, 1249-1258. [CrossRef]

40. Roeth, J.F.; Williams, M.; Kasper, M.R.; Filzen, T.M.; Collins, K.L. HIV-1 Nef disrupts MHC-I trafficking by recruiting AP-1 to the MHC-I cytoplasmic tail. J. Cell Biol. 2004, 167, 903-913. [CrossRef]

41. Singh, R.K.; Lau, D.; Noviello, C.M.; Ghosh, P.; Guatelli, J.C. An MHC-I cytoplasmic domain/HIV-1 Nef fusion protein binds directly to the mu subunit of the AP-1 endosomal coat complex. PLoS ONE 2009, 4, e8364. [CrossRef]

42. Aiken, C.; Krause, L.; Chen, Y.L.; Trono, D. Mutational analysis of HIV-1 Nef: Identification of two mutants that are temperaturesensitive for CD4 downregulation. Virology 1996, 217, 293-300. [CrossRef]

43. Williams, M.; Roeth, J.F.; Kasper, M.R.; Filzen, T.M.; Collins, K.L. Human immunodeficiency virus type 1 Nef domains required for disruption of major histocompatibility complex class I trafficking are also necessary for coprecipitation of Nef with HLA-A2. J. Virol. 2005, 79, 632-636. [CrossRef]

44. Williams, M.; Roeth, J.F.; Kasper, M.R.; Fleis, R.I.; Przybycin, C.G.; Collins, K.L. Direct binding of human immunodeficiency virus type 1 Nef to the major histocompatibility complex class I (MHC-I) cytoplasmic tail disrupts MHC-I trafficking. J. Virol. 2002, 76, 12173-12184. [CrossRef] [PubMed]

45. Wonderlich, E.R.; Williams, M.; Collins, K.L. The tyrosine binding pocket in the adaptor protein 1 (AP-1) mu1 subunit is necessary for Nef to recruit AP-1 to the major histocompatibility complex class I cytoplasmic tail. J. Biol. Chem. 2008, 283, 3011-3022. [CrossRef]

46. Yi, L.; Rosales, T.; Rose, J.J.; Chowdhury, B.; Knutson, J.R.; Venkatesan, S. HIV-1 Nef binds a subpopulation of MHC-I throughout its trafficking itinerary and down-regulates MHC-I by perturbing both anterograde and retrograde trafficking. J. Biol. Chem. 2010, 285, 30884-30905. [CrossRef] [PubMed]

47. Hurley, J.H.; Bonifacino, J.S. Nef-arious goings-on at the Golgi. Nat. Struct. Mol. Biol. 2012, 19, 661-662. [CrossRef]

48. Jia, X.; Singh, R.; Homann, S.; Yang, H.; Guatelli, J.; Xiong, Y. Structural basis of evasion of cellular adaptive immunity by HIV-1 Nef. Nat. Struct. Mol. Biol. 2012, 19, 701-706. [CrossRef]

49. Schaefer, M.R.; Wonderlich, E.R.; Roeth, J.F.; Leonard, J.A.; Collins, K.L. HIV-1 Nef targets MHC-I and CD4 for degradation via a final common beta-COP-dependent pathway in T cells. PLoS Pathog. 2008, 4, e1000131. [CrossRef]

50. Bresnahan, P.A.; Yonemoto, W.; Ferrell, S.; Williams-Herman, D.; Geleziunas, R.; Greene, W.C. A dileucine motif in HIV-1 Nef acts as an internalization signal for CD4 downregulation and binds the AP-1 clathrin adaptor. Curr. Biol. 1998, 8, 1235-1238. [CrossRef] 
51. Craig, H.M.; Pandori, M.W.; Guatelli, J.C. Interaction of HIV-1 Nef with the cellular dileucine-based sorting pathway is required for CD4 down-regulation and optimal viral infectivity. Proc. Natl. Acad. Sci. USA 1998, 95, 11229-11234. [CrossRef]

52. Macchi, B.; Graziani, G.; Zhang, J.; Mastino, A. Emergence of double-positive CD4/CD8 cells from adult peripheral blood mononuclear cells infected with human T cell leukemia virus type I (HTLV-I). Cell Immunol. 1993, 149, 376-389. [CrossRef]

53. Piguet, V.; Gu, F.; Foti, M.; Demaurex, N.; Gruenberg, J.; Carpentier, J.L.; Trono, D. Nef-induced CD4 degradation: A diacidicbased motif in Nef functions as a lysosomal targeting signal through the binding of beta-COP in endosomes. Cell 1999, 97, 63-73. [CrossRef]

54. Chaudhuri, R.; Mattera, R.; Lindwasser, O.W.; Robinson, M.S.; Bonifacino, J.S. A basic patch on alpha-adaptin is required for binding of human immunodeficiency virus type 1 Nef and cooperative assembly of a CD4-Nef-AP-2 complex. J. Virol. 2009, 83, 2518-2530. [CrossRef] [PubMed]

55. Jin, Y.J.; Cai, C.Y.; Zhang, X.; Zhang, H.T.; Hirst, J.A.; Burakoff, S.J. HIV Nef-mediated CD4 down-regulation is adaptor protein complex 2 dependent. J. Immunol. 2005, 175, 3157-3164. [CrossRef]

56. Stove, V.; Van de Walle, I.; Naessens, E.; Coene, E.; Stove, C.; Plum, J.; Verhasselt, B. Human immunodeficiency virus Nef induces rapid internalization of the T-cell coreceptor CD8alphabeta. J. Virol. 2005, 79, 11422-11433. [CrossRef]

57. Leonard, J.A.; Filzen, T.; Carter, C.C.; Schaefer, M.; Collins, K.L. HIV-1 Nef disrupts intracellular trafficking of major histocompatibility complex class I, CD4, CD8, and CD28 by distinct pathways that share common elements. J. Virol. 2011, 85, 6867-6881. [CrossRef]

58. Swigut, T.; Shohdy, N.; Skowronski, J. Mechanism for down-regulation of CD28 by Nef. EMBO J. 2001, 20, 1593-1604. [CrossRef]

59. Pereira, E.A.; da Silva, L.L. HIV-1 Nef: Taking control of protein trafficking. Traffic 2016, 17, 976-996. [CrossRef] [PubMed]

60. Craig, H.M.; Reddy, T.R.; Riggs, N.L.; Dao, P.P.; Guatelli, J.C. Interactions of HIV-1 nef with the mu subunits of adaptor protein complexes 1, 2, and 3: Role of the dileucine-based sorting motif. Virology 2000, 271, 9-17. [CrossRef] [PubMed]

61. Greenberg, M.; DeTulleo, L.; Rapoport, I.; Skowronski, J.; Kirchhausen, T. A dileucine motif in HIV-1 Nef is essential for sorting into clathrin-coated pits and for downregulation of CD4. Curr. Biol. 1998, 8, 1239-1242. [CrossRef]

62. Obermaier, B.; Ananth, S.; Tibroni, N.; Pierini, V.; Shytaj, I.L.; Diaz, R.S.; Lusic, M.; Fackler, O.T. Patient-derived HIV-1 Nef alleles reveal uncoupling of CD4 downregulation and SERINC5 antagonism functions of the viral pathogenesis factor. J. Acquir. Immune Defic. Syndr. 2020, 85, e23-e26. [CrossRef]

63. Heigele, A.; Kmiec, D.; Regensburger, K.; Langer, S.; Peiffer, L.; Sturzel, C.M.; Sauter, D.; Peeters, M.; Pizzato, M.; Learn, G.H.; et al. The potency of Nef-mediated SERINC5 antagonism correlates with the prevalence of primate lentiviruses in the wild. Cell Host Microbe 2016, 20, 381-391. [CrossRef]

64. Mwimanzi, P.; Markle, T.J.; Martin, E.; Ogata, Y.; Kuang, X.T.; Tokunaga, M.; Mahiti, M.; Pereyra, F.; Miura, T.; Walker, B.D.; et al. Attenuation of multiple Nef functions in HIV-1 elite controllers. Retrovirology 2013, 10, 1. [CrossRef]

65. Ren, X.; Park, S.Y.; Bonifacino, J.S.; Hurley, J.H. How HIV-1 Nef hijacks the AP-2 clathrin adaptor to downregulate CD4. eLife 2014, 3, e01754. [CrossRef]

66. Little, S.J.; Riggs, N.L.; Chowers, M.Y.; Fitch, N.J.; Richman, D.D.; Spina, C.A.; Guatelli, J.C. Cell surface CD4 downregulation and resistance to superinfection induced by a defective provirus of HIV-1. Virology 1994, 205, 578-582. [CrossRef] [PubMed]

67. Tanaka, M.; Ueno, T.; Nakahara, T.; Sasaki, K.; Ishimoto, A.; Sakai, H. Downregulation of CD4 is required for maintenance of viral infectivity of HIV-1. Virology 2003, 311, 316-325. [CrossRef]

68. Volsky, D.J.; Simm, M.; Shahabuddin, M.; Li, G.; Chao, W.; Potash, M.J. Interference to human immunodeficiency virus type 1 infection in the absence of downmodulation of the principal virus receptor, CD4. J. Virol. 1996, 70, 3823-3833. [CrossRef]

69. Benson, R.E.; Sanfridson, A.; Ottinger, J.S.; Doyle, C.; Cullen, B.R. Downregulation of cell-surface CD4 expression by simian immunodeficiency virus Nef prevents viral super infection. J. Exp. Med. 1993, 177, 1561-1566. [CrossRef] [PubMed]

70. Tremblay, M.; Meloche, S.; Gratton, S.; Wainberg, M.A.; Sekaly, R.P. Association of p56lck with the cytoplasmic domain of CD4 modulates HIV-1 expression. EMBO J. 1994, 13, 774-783. [CrossRef]

71. Chun, T.W.; Nickle, D.C.; Justement, J.S.; Meyers, J.H.; Roby, G.; Hallahan, C.W.; Kottilil, S.; Moir, S.; Mican, J.M.; Mullins, J.I.; et al. Persistence of HIV in gut-associated lymphoid tissue despite long-term antiretroviral therapy. J. Infect. Dis. 2008, 197, 714-720. [CrossRef] [PubMed]

72. Klatt, N.R.; Chomont, N.; Douek, D.C.; Deeks, S.G. Immune activation and HIV persistence: Implications for curative approaches to HIV infection. Immunol. Rev. 2013, 254, 326-342. [CrossRef]

73. Brenchley, J.M.; Price, D.A.; Schacker, T.W.; Asher, T.E.; Silvestri, G.; Rao, S.; Kazzaz, Z.; Bornstein, E.; Lambotte, O.; Altmann, D.; et al. Microbial translocation is a cause of systemic immune activation in chronic HIV infection. Nat. Med. 2006, 12, 1365-1371. [CrossRef] [PubMed] 